\title{
Relationship between prosthetic factors and oral health-related quality of life in complete denture wearers
}

\author{
Vagner Flávio Reginatoa ${ }^{\mathrm{a}}$ Angélica Maroli ${ }^{\mathrm{b}}$, Ricardo Armini Caldas ${ }^{\mathrm{a}}$, Alfonso Sánchez-Ayala ${ }^{\mathrm{c}}$, \\ Aloísio Oro Spazzin ${ }^{d}$, Ataís Bacchid
}

\begin{abstract}
OBJECTIVE: The aim of this study was to evaluate the influence of prosthetic-related factors on OHRQOL

METHODS: Twenty-eight edentulous patients, conventional complete dentures wearers, composed the sample. The evaluation of prosthetic factors involved the clinical assessment of quality of dentures, patients' satisfaction, and masticatory ability, as well as recording of wearing time. The OHRQoL was determined thought the oral health impact profile (OHIP-EDENT) questionnaire. Pearson's correlation coefficient and stepwise multiple linear regression analysis were used to statistical inferences $(\alpha=0.05)$.

RESULTUS: The OHRQoL showed a strong correlation with the masticatory ability $(r=0.8 / p<0.001)$ and patients' satisfaction $(r=0.7 / p<0.001)$, which also displayed a strong correlation between them $(r=0.7 / p<0.001)$. Moreover, the regression model stated that these variables explained $68.2 \%$ $\left(r^{2}=0.682\right)$ of the variation in the OHIP-EDENT data $(p<0.001)$.

CONCLUSION: The OHRQoL was influenced by prosthetic factors, when these were characterized by the masticatory ability and patients' satisfaction, and not by the quality of dentures nor wearing time.
\end{abstract}

Key words: Quality of life; Mastication; Patient satisfaction; Denture, complete; Prosthodontics

\section{Relação entre fatores protéticos e qualidade de vida autorrelatada em portadores de próteses totais}

\section{RESUMO}

OBJETIVO: O objetivo desse estudo foi avaliar os fatores relacionados ao uso de prótese na OHRQoL. MÉTODOS: Vinte-oito pacientes edêntulos portadores de prótese total mucossuportada compuseram a amostra. A avaliação dos fatores relacionados ao uso de prótese envolveu a avaliação clínica da qualidade das próteses, a satisfação dos pacientes, habilidade mastigatória e o tempo de uso da prótese. A OHRQoL foi determinada através do questionário OHIP-EDENT. Coeficiente de correlação de Pearson e análise linear de regressão múltipla foram usados para análise estatística $(\alpha=0,05)$

RESULTADOS: A OHRQoL demonstrou forte correlação com a habilidade mastigatória $(r=0,8 / p<0,001)$ e com a satisfação do paciente $(r=0,7 / p<0,001)$, as quais ainda apresentaram forte correlação entre si $(r=0,7 / p<0,001)$. Ainda, a análise de regressão demonstrou que essas variáveis foram responsáveis pelos $68,2 \%\left(r^{2}=0,682\right)$ da variação apresentada pelos resultados do OHIP-EDENT $(p<0,001)$.

CONCLUSÃO: A OHRQoL foi influenciada pelos fatores habilidade mastigatória e satisfação dos pacientes, enquanto qualidade da prótese e tempo de uso não demonstraram influenciar qualidade de vida auto relatada.

Palavras-chave: Qualidade de vida; Mastigação; Satisfação do paciente; Prótese total; Prótese a Department of Prosthodontics and Periodontology Piracicaba Dental School, University of Campinas, Piracicaba, São Paulo, Brazil

${ }^{b}$ Meridional Faculty, Dental School, Passo Fundo, Rio Grande do Sul, Brazil

${ }^{c}$ Department of Dentistry, University of Ponta Grossa, Ponta Grossa, Paraná, Brazil

d Department of Prosthodontics, Dental School, Meridional Faculty, Passo Fundo, Rio Grande do Sul, Brazil 


\section{INTRODUCTION}

Rehabilitation of edentulous patients remains one of the most challenging treatment modalities. Although the current supported or retained implant denture therapies are the ideal choices, treatment with muco-supported complete dentures is the most common alternative for edentulous subjects, especially because of its cost-effective scope [1]. However, the functional, aesthetic and psychological edentulism complaints, even with an appropriated planning, could not often be immediately and definitely resolved with the conventional techniques of complete dentures [1]. Thus, the successful treatment depends on patient's ability to use the dentures through adapting to the new oral environment. This process becomes critical in old age, where adjustment to dentures has to compete with other chronic problems and, the coping behavior of patients is gradually diminished [2].

Each patient develops different oral experiences with new well-constructed complete dentures, involving sensorimotor changes as well as integration of higher braincenter functions related to past experiences, expectations, and attitudes [3]. It can be considered that few weeks are sufficient to speak normally after some practice with them. A period of 6 to 8 weeks is necessary to allow satisfactory mastication by the establishment of new muscle engrams [4].

Oral Health related-Quality of life (OHRQoL) describes subject's comfort degree when eating, sleeping and engaging in social relations, self-confidence, and perception regarding to their oral health [5]. Improvement in the OHRQoL of patients complete denture wearers are evident independently from the severity of condition, but mainly in the severe cases with unfavorable residual ridge, mucous membrane, skeletal relationship, oral habits, and other traits such as the presence of torus and alteration on the amount and nature of saliva [6]. Thus, the OHRQoL should be influenced by the technical quality of denture, auto-perception about the treatment or patients' satisfaction, functionality or masticatory ability, and aging or wearing time. However, conclusions on this topic are difficult to trace because studies evaluating simultaneously these factors are limited.

Considering the exposed above, the aim of this study was to evaluate the influence of quality of dentures, patients' satisfaction, masticatory ability, and wearing time on oral health-related quality of life (OHRQoL) of complete denture wearers.

\section{METHODOS}

\section{Study design}

This clinical study allowed a cross-sectional design and was conducted in a sample of both complete maxillary and mandibular denture wearers. The OHRQoL of subjects was evaluated by the use of the 19-item Oral health Impact Profile (OHIP-EDENT) questionnaire, where the obtained scores were considered as the dependent variable. After that, a calibrated examiner, blind to the OHRQoL results, assessed the independent variables quality of denture, masticatory ability and overall satisfaction. All variables were correlated to each other, and then, a multiple linear regression analysis was applied.

\section{Sample}

Twenty-eight complete denture wearers were recruited by convenience sampling from institutionalized older persons over sixty years. The broad inclusion criteria applied were to have a good general health and satisfactory cognitive ability and understanding to respond to the proposed questions in the present study, and to wear the current dentures for at least 12 months. Patients were excluded if they exhibited no controlled systemic diseases, motor disorders, temporomandibular disorders diagnosed by the Research Diagnostic Criteria, xerostomia clinically determined, or oral manifestations of systemic diseases. The protocol was approved by the local Ethics Committee, and all participants received information about the evaluation procedures and signed an informed consent form.

\section{OHRQoL measurement}

Subjects were evaluated through the 19-item Oral health Impact Profile self-filled questionnaire specific for edentulous patients (OHIP-EDENT), which is based on the original OHIP proposed by Slade in 1994 [7]. Due to sample nature, it was applied a validated version for the Brazilian Portuguese language [8]. Scoring was calculated by assigning points to the answers $(1=$ never; $2=$ sometimes; $3=$ almost always). The OHIP-EDENT scores were examined over four domains [9]: masticatory-related complaints (questions $1,5,10$, and 11), psychological discomfort and disability (questions 8, 9, 12,13, and 14), social disability (questions 15-19), and oral pain and discomfort (questions 2-4, 6, and 7).

\section{Technical quality of complete dentures}

The assessment of quality of dentures was performed according to protocol based on clinical criterions established by Sato et al. [10]. The examiners first observed the denture appearance outside of the mouth, then evaluated the dentures in the mouth with fingers and/or instruments, and finally assessed the dentures outside the mouth (12). This method takes into consideration the following parameters: (1) Arrangement of anterior teeth; (2) interoclusal space; (3) stability of mandibular denture; (4) occlusion; (5) articulation; (6) retention of the mandibular denture; (7) border extension of the mandibular denture. The three grades answered were considered. A scoring method employed the seven more from sixteen influential quality factors on the general impression of the dentures, based on the level of contribution of each factor in a multivariate regression model. Category scores for each factor were calculated and then converted into an integer such that the sum of the category scores of the remaining significant factors was distributed from 0 to 100 . That is, category scores for grade 3 were converted to 0 , and sum of grade 2 and 3 were converted to 51 and 100 , respectively [10]. 
The converted sum determined the complete denture quality score.

\section{Masticatory ability}

The evaluation of masticatory ability was realized through a questioner established by Bajoria et al. [11]. The patient pointed self-related scores answering the questions about the ability or lack of ability to comminute hard and soft foods, relating it with the discomfort and instability of the dentures, with perception of satisfaction in relation to the aesthetics, to the pleasure when eating, to the level of comfort and to the assurance with them. The examiner was responsible only for the explanation of probable doubts that could arise with the questions and answers, but not affecting with their contents.

\section{Overall satisfaction}

Visual analogue scale (VAS) was employed to determine overall satisfaction. Subjects were asked to describe their degree of general satisfaction with their dentures and also to rate satisfaction with maxillary and mandibular dentures independently for aesthetics, comfort, stability, ability to chew and to speak [12]. The VAS consisted of a horizontal $100 \mathrm{~mm}$ line limited by the terms "completely dissatisfied" at one extremity of the scale and "completely satisfied" at the other end. Subjects were instructed to mark a line at a point corresponding to their satisfaction level, and the value was registered as the distance in millimeters from the left end to the subject mark such that higher values indicated a high level of satisfaction.

\section{Statistical analysis}

All data were collected by a single calibrated examiner. Data were explored using SPSS ${ }^{\circledR}$ software (version 20; IBM, Armonk, NY, USA), and all inferences were performed with two-tailed trials using a significance level of $95 \%$ and statistical power of $80 \%$. An additive method was used to calculate the overall values to OHRQoL and masticatory ability. Thus, the response codes for the each item from each questionnaire were summed and their results transformed to percentage according to the higher value (57 points and 40 points, respectively). A simple count method was utilized to determine the overall value to quality of dentures. Multiple linear regression analysis was used to examine the relationship between the independent variables wearing time, satisfaction, masticatory ability and quality of dentures, and the dependent variable quality of life. A stepwise method was used, were at each step, the independent variable not in the equation that has the smallest probability of $F$ is entered, if that probability is sufficiently small; variables already in the regression equation are removed if their probability of $F$ becomes sufficiently large. Then, this method terminates when no more variables are eligible for inclusion or removal. All values were considered as ratio-level variables. Assumptions of normality examined by histograms and normal probability plots for each variable were met. Descriptive statistic showed that values for skewness and the kurtosis indices were small $(>3$ or $<-3$ ), which indicates that the variables most likely do not include influential cases or outliers. By the use of Pearson's correlation coefficient, OHIP-EDENT data met the assumption of linearity regarding explanatory variables, except to wearing time. However, this violation must be noted as a limitation of the model.

\section{RESULTS}

Outcomes from answers for OHIP-EDENT and masticatory ability questionnaires are showed in Table $\mathbf{1}$ and 3. Examiner's appreciations regarding quality of dentures are also presented in Table 2. Wearing time and overall satisfaction presented means values of $17.8 \pm 2.4$ years and $73.5 \pm 5.2 \mathrm{~mm}$ (VAS), respectively. Participants were between 60 and 78 years of age, with a mean age of $66.2 \pm 3.4$ years. The quality of life showed strong correlation with masticatory ability $(\mathrm{r}=0.8 / p<0.001)$ and overall satisfaction $(\mathrm{r}=0.7 / p<0.001)$. A strong correlation was also found $(\mathrm{r}=0.7 / p<0.001)$ between masticatory ability and overall satisfaction (Table 4).

Masticatory ability and satisfaction were the variables that showed influence on the quality of life. The regression model stated that this variable explained $68.2 \%\left(\mathrm{r}^{2}=0.682\right)$ of the variation in the OHIP-EDENT, exhibiting a $p$ values for the $F$ statistic $<0.001$. Multicollinearity was not a limitation of model because the variance inflation factor scores from the explanatory variables was $<3$ (tolerance criteria).

Table 1. Application results of OHIP-EDENT. Frequency (percentage) and additive score (ADD) of answers for each question of the OHIP-EDENT $(n=28)$.

\begin{tabular}{lcccc}
\hline \multirow{2}{*}{ Questions never } & \multicolumn{4}{c}{ Answers } \\
\cline { 2 - 5 } & Sometimes & $\begin{array}{c}\text { Almost } \\
\text { always }\end{array}$ & ADD \\
1. Difficulty chewing & $9(32.1)$ & $5(17.9)$ & $14(50.0)$ & 72.6 \\
2. Food catching & $12(42.9)$ & $7(25.0)$ & $9(32.1)$ & 63.1 \\
3. Dentures not fitting & $13(46.4)$ & $3(10.7)$ & $12(42.9)$ & 65.5 \\
4. Painful aching & $6(21.4)$ & $9(32.1)$ & $13(46.4)$ & 75.0 \\
5. Uncomfortable to eat & $6(21.4)$ & $9(32.1)$ & $13(46.4)$ & 75.0 \\
6. Sore spot & $8(28.6)$ & $6(21.4)$ & $14(50.0)$ & 73.8 \\
7. Uncomfortable dentures & $13(46.4)$ & $5(17.9)$ & $10(35.7)$ & 63.1 \\
8. Worried & $7(25.0)$ & $17(60.7)$ & $4(14.3)$ & 63.1 \\
9. Self-conscious & $2(7.1)$ & $6(21.4)$ & $20(71.4)$ & 88.1 \\
10. Avoids eating & $5(17.9)$ & $9(32.1)$ & $14(50.0)$ & 77.4 \\
11. Interrupts meals & $4(14.3)$ & $7(25.0)$ & $17(60.7)$ & 82.1 \\
12. Unable to eat & $2(7.1)$ & $3(10.7)$ & $23(82.1)$ & 91.7 \\
13. Upset & $1(3.6)$ & $4(14.3)$ & $23(82.1)$ & 92.9 \\
14. Has been embarrassed & $1(3.6)$ & $4(14.3)$ & $23(82.1)$ & 92.9 \\
15. Avoids going out & $1(3.6)$ & $0(0.0)$ & $27(96.4)$ & 97.6 \\
16. Less tolerant of others & $1(3.6)$ & $0(0.0)$ & $27(96.4)$ & 97.6 \\
17. Irritable with others & $1(3.6)$ & $3(10.7)$ & $24(85.7)$ & 94.0 \\
18. Unable to enjoy company & $0(0.0)$ & $2(7.1)$ & $26(92.9)$ & 97.6 \\
19. Life unsatisfying & $0(0.0)$ & $5(17.9)$ & $23(82.1)$ & 94.0 \\
Mean of individual scores & & $82.0 \pm 12.8$ & \\
\hline
\end{tabular}


Table 2. Frequency (percentage) of quality of denture's factors and converted integer numbers of category scores $(n=28)$.

\begin{tabular}{|c|c|c|c|c|c|c|c|}
\hline \multirow{2}{*}{ Factors } & \multicolumn{3}{|c|}{ Examiner's appreciation } & \multicolumn{3}{|c|}{$\begin{array}{l}\text { Converted integers from } \\
\text { category scores }\end{array}$} & \multirow{2}{*}{$\begin{array}{l}\text { Quality of } \\
\text { denture's factors }\end{array}$} \\
\hline & Grade 1 & Grade 2 & Grade 3 & Grade 1 & Grade 2 & Grade 3 & \\
\hline Anterior teeth arrangement & $6(21.4)$ & $15(53.6)$ & $7(25.0)$ & 13 & 2 & 0 & 3.9 \\
\hline Interocclusal distance & $17(60.7)$ & $9(32.1)$ & $2(7.1)$ & 12 & 1 & 0 & 7.6 \\
\hline Stability of mandibular denture & $4(14.3)$ & $13(46.4)$ & $11(39.3)$ & 12 & 8 & 0 & 5.4 \\
\hline Occlusion & $6(21.4)$ & $0(0.0)$ & $22(78.6)$ & 14 & 13 & 0 & 3.0 \\
\hline Articulation & $6(21.4)$ & $2(7.1)$ & $20(71.4)$ & 16 & 8 & 0 & 4.0 \\
\hline Retention of mandibular denture & $2(7.1)$ & $9(32.1)$ & $17(60.7)$ & 15 & 11 & 0 & 4.6 \\
\hline Border extension of mandibular denture & $1(3.6)$ & $26(92.9)$ & $1(3.6)$ & 18 & 8 & 0 & 8.1 \\
\hline Score for denture quality & \multicolumn{7}{|c|}{$36.6 \pm 19.9$} \\
\hline
\end{tabular}

Table 3. Frequency (percentage) and additive score (ADD) of answers for each question of masticatory ability questionnaire $(n=28)$.

\begin{tabular}{|c|c|c|c|c|c|c|}
\hline \multirow[b]{2}{*}{ Questions total satisfaction } & \multicolumn{6}{|c|}{ Answers } \\
\hline & Satisfied & Not sure & Dissatisfied & $\begin{array}{l}\text { Total } \\
\text { dissatisfaction }\end{array}$ & ADD & \\
\hline $\begin{array}{l}\text { 1. Is there any change on chewing with the artificial teeth compared with your } \\
\text { natural teeth; is it better now? }\end{array}$ & $14(50.0)$ & $7(25.0)$ & $1(3.6)$ & $4(14.3)$ & $2(7.1)$ & 74.1 \\
\hline 2. Are you satisfied with the eating habits with the artificial teeth? & $3(10.7)$ & $16(57.1)$ & $2(7.1)$ & $6(21.4)$ & $1(3.6)$ & 62.5 \\
\hline 3. Are you feeling conscious while having meals with the denture? & $3(10.7)$ & $17(60.7)$ & $4(14.3)$ & $4(14.3)$ & $0(0.0)$ & 67.0 \\
\hline 4. Is there any difficulty in chewing any type of food with artificial teeth? & $1(3.6)$ & $13(46.4)$ & $0(0.0)$ & $12(42.9)$ & $2(7.1)$ & 49.1 \\
\hline $\begin{array}{l}\text { 5. Is there a need for special food preparation for you to make chewing food } \\
\text { easier? [e.g. moistening, pureeing, cutting into small parts etc.] }\end{array}$ & $0(0.0)$ & $12(42.9)$ & $0(0.0)$ & $12(42.9)$ & $4(14.3)$ & 42.9 \\
\hline 6. How stable is your denture on eating sticky food? & $1(3.6)$ & $10(35.7)$ & $1(3.6)$ & $13(46.4)$ & $3(10.7)$ & 43.8 \\
\hline 7. Is there any force needed to swallow the food? & $5(17.9)$ & $18(64.3)$ & $0(0.0)$ & $4(14.3)$ & $1(3.6)$ & 69.6 \\
\hline 8. Have you ever faced any difficulty with the denture between meals? & $2(7.1)$ & $17(60.7)$ & $2(7.1)$ & $6(21.4)$ & $1(3.6)$ & 61.6 \\
\hline 9. Compared with others, do you feel you take a longer time for chewing food? & $1(3.6)$ & $21(75.0)$ & $4(14.3)$ & $1(3.6)$ & $1(3.6)$ & 67.9 \\
\hline 10. Are you embarrassed on having food with others? & $2(7.1)$ & $23(82.1)$ & $2(7.1)$ & $1(3.6)$ & $0(0.0)$ & 73.2 \\
\hline Mean of individual scores & \multicolumn{6}{|c|}{$61.2 \pm 14.8$} \\
\hline
\end{tabular}

Table 4. Correlation coefficients $(r)$ among variables used in the model $(n=28)$.

\begin{tabular}{llcccc}
\hline Variables & $\mathbf{1}$ & $\mathbf{2}$ & $\mathbf{3}$ & $\mathbf{4}$ \\
1 & Quality of life & - & - & - & - \\
2 & Masticatory ability & $0.784^{\star \star}$ & - & - & - \\
3 & Quality of dentures & 0.372 & 0.294 & - & - \\
4 & Wearing time & 0.112 & -0.040 & -0.096 & - \\
5 & Overall satisfaction & $0.723^{\star \star}$ & $0.677^{\star *}$ & 0.322 & 0.163 \\
\hline
\end{tabular}

* Correlation is significant at the 0.05 level.

** Correlation is significant at the 0.001 level.

The residuals histogram showed a normal distribution, therefore, the normality of residuals assumption was satisfied. A scatter plot of the residuals against the predicted values described any pattern, thus, the homogeneity of variance assumption was also met. Data did not include outliers or influential cases because results showed no standardized Dfbeta values $<-2$ or $>2$.

\section{DISCUSSION}

Results from the present study indicated that independently to technical quality and age of dentures, the ability to chew and treatment approval are fundamental to increase the OHRQoL. Apparently, masticatory function in edentulous could be affected by mechanical advantages from anatomical factors, such as skeletal features [13], muscle force [14] and alveolar ridge characteristics [6], and from prosthetic factors, such as retention, stability, support [15], occlusal scheme, area and contacts, and cusp angles [16]. However, the neuromuscular ability to move strategically the mandible, tongue, cheeks and lips to select and capture food particles between teeth can be the key to develop a higher capacity to use bimaxillary complete dentures in an effective form. Then, if the food particles are not efficiently selected and distributed on artificial teeth, their mechanical potential for breakdown may be useless.

During mastication, jaw-closing and jaw-opening muscles are triggered by the motor cortex, and controlled through bilaterally descending corticobulbar projections to the trigeminal motor nuclei and brainstem reticular formation in the pons [17]. Motor cortex initiates and stops the masticatory sequences and determines preprogrammed movement patterns, which may be modified by expectations and feedback. Under voluntary control, mastication mainly performs automatically, such that slight conscious effort is necessary once mandibular movement is initiated. 
Corticobulbar projections to the reticular formation are assumed to mediate voluntary control over the central pattern generator $(\mathrm{CPG})$ for masticatory movements. The $\mathrm{CPG}$ supplies the basic rhythmic activity, which are continuously regulated by peripheral inputs according to changes in food texture and oral conditions [17].

With the loss of all teeth, the efficiency of masticatory apparatus is expressively decreased. The elimination of pulpal and periodontal mechanoreceptor alters the fine proprioceptive control of mandibular movement and modifies the precision of magnitude, direction, and rate of occlusal force [18]. The reduced discriminative sensory information from the trigeminal paths and the deteriorated function cannot be completely retrieved with the use of conventional complete denture. However, it should be recognized the adaptability of the neuromuscular system in at least conserving partially the oral stereognosis. Alternative receptors could take over the role of the lost periodontal receptors. This input may be transmitted from joints, muscle, cutaneous, mucosal, and/or periosteal mechanoreceptors, providing information about jaw function and artificial tooth contacts [18].

Besides the tongue functions of rotation, tilting and pushing of the food for the occlusal selection, additional functional demands are placed on it during mastication. Although only few patients are able to analyze the mechanisms of using their tongues to stabilize their mandibular denture, it has been determined that the tongue has an influence on retention by tactile localization of denture, lateral stability during chewing and biting, and denture stabilization against front displacement [19]. It also was determined that maxillary denture retention by tongue support and adequate resistance to vertical pull, and mandibular stability by resistance to anterior-posterior movements were associated with the individuals' oral health-related well being [10]. The main cheek movement is pushing the food medially, and their pressure against the vestibular flange together with the lips seem to have less importance [21].

Although the self-perception of masticatory function is optimist in comparison to an objective measurement, such as masticatory performance, masticatory ability could be a better predictor of OHRQoL than the number of natural teeth, functional tooth units, and posterior occlusal contacts in elderly [22]. Perceived masticatory ability is also a critical factor for OHRQoL variation, but masticatory performance rather than food mixing ability is important for masticatory ability and OHRQoL in removable partial dentures wearers. Moreover, there is a relationship of masticatory ability with leg extensor strength, one-leg standing time, and isokinetic leg extensor power [23]. Other factors, such as, psychological, cultural and socio-demographic variables may explain the $31.8 \%$ of influence that the model power does not consider.

It has been suggested that other factors such as attitude towards dentures, number of previous dentures, patients' personality and expectations, patient-dentist relationship and even the judgment of dentists' qualifications and skills may have an important role on subjects' final judgment of treatment [12]. The lack of influence of technical quality and age of dentures may be explained because the edentulous subjects will have a different time to adapt to dentures and appreciate them, but possibly a denture with technical quality may increase the chances of treatment success. When the natural deterioration of dentures arrives and after that, an effective masticatory adaptation could avoid an unfavorable assessment of them. The inverse route would hardly be taken, because a patient will hardly adapt to dentures with lack of technical quality from the beginning. Although the subjective evaluations of the patients are important for the measurement of the satisfaction of the prosthetic rehabilitations, the technical quality of the prostheses is also a primordial factor [24].

It must be considered that the identification of correlates of epidemiologic profile and self-perceived oral health are complex issues. Several factors might influence selfreported quality of life, including anatomy, ability to chew, ability to speak, esthetics, psychological characteristics, and patient adaptation to dentures. In the same way, different methods can be used to evaluate the patients, with potential of different analyzes [25]. Therefore, some limitations of the represent study might include limited sample and clinical measures, no valid indicators of patients' denture experience, limited patient-reported measures in evaluations of complete dentures, contribution of socio-demographics, age of the subjects, medical and dental factors on the profile and selfperceived oral health.

\section{CONCLUSION}

In conclusion, this study has shown that masticatory efficacy and overall satisfaction present significant influence on the OHRQoL in complete denture wearers subjects, while the time of wear and the technical quality of denture did not influence. The overall satisfaction has shown strong correlation with masticatory efficacy.

\section{REFERENCES}

1. Cunha TR, Della Vecchia MP, Regis RR, Ribeiro AB, Muglia VA, Mestriner W $\mathrm{Jr}$, de Souza RF. A randomised trial on simplified and conventional methods for complete denture fabrication: masticatory performance and ability. J Dent. 2013; 41(2):133-42. https://doi.org/10.1016/j.jdent.2012.09.008

2. Garrett NR, Perez P, Elbert C, Kapur KK. Effects of improvements of poorly fitting dentures and new dentures on masticatory performance. J Prosthet Dent. 1996;75(4):269-75. https://doi.org/10.1016/S0022-3913(96)90483-7

3. Luraschi J, Korgaonkar MS, Whittle T, Schimmel M, Müller F, Klineberg I. Neuroplasticity in the adaptation to prosthodontic treatment. J Orofac Pain. 2013;27(3):206-16

4. Zarb G, Hobkirk JA, Eckert SE, Jacob RF. Prosthodontic Treatment for Edentulous Patients: Complete Dentures and Implant-Supported Prostheses. Mosby Elsevier. 2012;13(1):162-9

5. Sischo L, Broder HL. Oral health-related quality of life: what, why, how and future implications. J Dent Res. 2011;90(19):1264-70. https://doi. org/10.1177/0022034511399918

6. Kurushima Y, Matsuda K, Enoki K, Ikebe K, Maeda Y. Does case severity make a difference to clinical improvement following complete denture treatment? Int J Prosthodont. 2015;28(2):161-6. https://doi.org/10.11607/ ijp. 4177

7. Slade GD, Spencer AJ. Development and evaluation of the Oral Health Impact Profile. Community Dent Health. 1994;11(2):3-11. 
8. Souza RF, Patrocínio L, Pero AC, Marra J, Compagnoni MA. Reliability and validation of a Brazilian version of the Oral Health Impact Profile for assessing edentulous subjects. J Oral Rehabil. 2007:34(3):821-6. https:// doi.org/10.1111/j.1365-2842.2007.01749.x

9. Souza RF, Leles CR, Guyatt GH, Pontes CB, Della Vecchia MP, Neves FD. Exploratory factor analysis of the Brazilian OHIP for edentulous subjects. J Oral Rehabil. 2010;37(3):202-8. https://doi.org/10.1111/j.13652842.2009.02043.x

10. Sato $Y$, Tsuga $K$, Akagawa $Y$, Tenma H. A method for quantifying complete denture quality. J Prosthet Dent. 1998;80(13):52-7. https://doi.org/10.1016/ S0022-3913(98)70091-5

11. Bajoria AA, Saldanha S, Shenoy VK. Evaluation of satisfaction with masticatory efficiency of new conventional complete dentures in edentulous patients--a survey. Gerodontology. 2012;29(3):231-8. https:// doi.org/10.1111/j.1741-2358.2012.00634.X

12. De Lucena SC, Gomes SG, Da Silva WJ, Del Bel Cury AA. Patients satisfaction and functional assessment of existing complete dentures: correlation with objective masticatory function. J Oral Rehabil 2011;38(6):440-6. https://doi.org/10.1111/j.1365-2842.2010.02174.x

13. Ochiai KT, Hojo S, Nakamura C, Ikeda H, Garrett NR. Impact of facial form on the relationship between conventional or implant-assisted mandibular dentures and masticatory function. J Prosthet Dent. 2011;105(4):256-65 https://doi.org/10.1016/S0022-3913(11)60041-3

14. Kapur KK, Garrett NR. Studies of biologic parameters for denture design Part II: Comparison of masseter muscle activity, masticatory performance, and salivary secretion rates between denture and natural dentition groups. J Prosthet Dent. 1984:52(11):408-13. https://doi.org/10.1016/00223913(84)90456-6

15. Darvell BW, Clark RK. The physical mechanisms of complete denture retention. Br Dent J. 2000;189(14):248-52. https://doi.org/10.1038/ sj.bdj.4800734a

16. Carlsson GE. Critical review of some dogmas in prosthodontics. J Prosthodont Res. 2009;53(1):3-10. https://doi.org/10.1016/j.jpor. 2008.08.003

17. Nordstrom MA. Insights into the bilateral cortical control of human masticatory muscles revealed by transcranial magnetic stimulation.
Arch Oral Biol. 2007:52(4):338-42. https://doi.org/10.1016/j.archoralbio. 2006.09.013

18. Klineberg I, Murray G. Osseoperception: sensory function and proprioception. Adv Dent Res. 1999;13(1):120-9. https://doi.org/10.1177 /08959374990130010101

19. Zmudzki J, Chladek W, Lipski T. Influence of tongue activity on lower complete denture retention under biting forces. Acta Bioeng Biomech 2008;10(1):13-20

20. Chen YF, Yang YH, Lee JH, Chen JH, Lee HE, Chou TM. Tongue support of complete dentures in the elderly. Kaohsiung J Med Sci. 2012:28(5):273-8. https://doi.org/10.1016/j.kjms.2011.11.005

21. Kawashima K, Miura H, Kato H, Yoshida K, Tanaka Y. The study of comminution behavior of food on buccal and lingual side during mastication. J Med Dent Sci. 2009;56(7):131-8.

22. Hsu KJ, Lee HE, Wu YM, Lan SJ, Huang ST, Yen YY. Masticatory factors as predictors of oral health-related quality of life among elderly people in Kaohsiung City, Taiwan. Qual Life Res. 2014;23(4):1395-405. https://doi. org/10.1007/s11136-013-0574-7

23. Takata Y, Ansai T, Awano S, Hamasaki T, Yoshitake Y, Kimura Y, Sonoki K, Wakisaka M, Fukuhara M, Takehara T. Relationship of physical fitness to chewing in an 80-year-old population. Oral Dis. 2004;10(1):44-9. https:// doi.org/10.1046/j.1354-523X.2003.00972.x

24. Cerutti-Kopplin D, Emami E, Hilgert JB, Hugo FN, Rivaldo E, Padilha DM. Predictors of Satisfaction with Dentures in a Cohort of Individuals Wearing Old Dentures: Functional Quality or Patient-Reported Measures? Journal of prosthodontics: official journal of the American College of Prosthodontists. 2015: 26(3):196-200

25. Ebell MH, Siwek J, Weiss BD, Woolf SH, Susman J, Ewigman B, Bowman M. Strength of recommendation taxonomy (SORT): a patient-centered approach to grading evidence in the medical literature. The Journal of the American Board of Family Practice / American Board of Family Practice. 2004;17(1):59-67. https://doi.org/10.3122/jabfm.17.1.59 